\title{
Cenário temático da pesquisa em educação ambiental no contexto da ANPEd
}

\author{
Vera Lessa Catalão ${ }^{1}$
}

Resumo: O presente artigo, resultado de trabalho apresentado em São Carlos no V Encontro de Pesquisa em Educação Ambiental (EPEA), tem como base uma pesquisa realizada por Pato, Sá e Catalão em 2008, sob encomenda do Grupo de Trabalho GT 22, para ser discutida na $31^{a}$ Reunião da Associação Nacional de Pós-Graduação e Pesquisa em Educação - ANPEd. O foco da pesquisa foi o conjunto de trabalhos apresentados ao GT 22 nas reuniões anuais da ANPEd no período de 2003 a 2007, com o objetivo de especificar as principais tendências temáticas, teóricas e metodológicas na produção acadêmica sobre EA e compreender a diversidade que constitui esse campo de investigação e de ação pedagógica. Foram analisados 66 trabalhos apresentados nas cinco reuniões consideradas. Os resultados foram articulados considerando-se: evolução da temática; linha temporal associada à diversificação temática, teórica e metodológica; localização espacial e articulação entre as áreas ambiental, de educação e de EA. Este artigo é um recorte da referida pesquisa e enfoca o cenário temático e sua diversidade no conjunto de trabalhos analisados.

Palavras-chave: Educação Ambiental, ANPEd, Grupo de Trabalho em Educação Ambiental GT 22, Tendências na Pesquisa em Educação Ambiental.

Abstract: The present paper, which is the result of a work presented at the Federal University of São Carlos, SP, during the V Research Meeting on Environmental Education (EE), is based upon a research conducted by Pato, Sá and Catalão in 2008, under request of GT 22 (Working Group), in occasion of the 31st Meeting of the National Postgraduate and Research Association for Environmental Education (ANPEd). The research focused on works presented to the GT 22 during the ANPEd annual meetings from 2003 to 2007, aiming at specifying the main thematic, theoretical and methodological tendencies in the production of EE by the academy, as well as at understanding the diversity that characterizes that field of investigation and pedagogical action. 66 papers from the five meetings considered were analyzed. Results were articulated considering: thematic evolution; timeline associated to the thematic, theoretical and methodological diversity; spatial localization and articulation between the environmental, educational and $\mathrm{EE}$ areas. This paper is a short version of the research mentioned

${ }^{1}$ Doutora em Ciências da Educação pela Universidade de Paris VIII, professora do Depto. de Teoria e Fundamentos - Faculdade de Educação da Universidade de Brasília. Contato: Campus Universitário Darcy Ribeiro, Asa Norte, Brasília - DF. CEP: 70.910-900.E-mail: vera.catalao@terra.com.br 
above and focuses on the thematic scenario and diversity of the set of works analyzed.

Keywords: Environmental Education, ANPEd, Working Group on Environmental Education - GT 22, Trends in Environmental Education Research.

\section{Introdução}

A partir da Rio-92, a educação ambiental no Brasil afirma-se cada vez mais por uma visão do meio ambiente como um campo de conhecimento e significados socialmente construído, marcado pela complexidade, pluralidade de interpretações e conflitos de interesses e abrindo um estimulante espaço para repensar as práticas sociais e o papel dos professores como mediadores e como transmissores de um conhecimento necessário para uma sociedade em plena crise ambiental. Diante da complexidade dos processos sociais e do aumento dos riscos ambientais, pergunta-se: que identidades surgem no cenário da educação ambiental na última década do século XX e na primeira década deste século?

Identificar quais as principais temáticas constitutivas desse campo de interlocução de que se ocupa a educação ambiental, as lentes teóricas e as metodologias que sustentam a investigação e a análise interpretativa na área constitui o objeto da pesquisa realizada por Pato, Sá e Catalão (2009) encomendada pelo GT 22, em 2008, para a 31 a Reunião da Associação Nacional de Pós-Graduação e Pesquisa em Educação - ANPEd. O foco da pesquisa foi o conjunto de trabalhos apresentados ao GT 22 nas reuniões anuais da ANPEd no período de 2003 a 2007, com o objetivo de especificar e compreender as principais tendências temáticas, teóricas e metodológicas na produção acadêmica sobre EA. O presente artigo é um recorte da referida pesquisa e aborda o universo temático da produção científica em educação ambiental evidenciado pela análise dos 66 trabalhos apresentados em cinco reuniões consideradas da ANPEd.

A educação ambiental brasileira, especialmente a partir da Conferência Rio-92, vem agregando notável conteúdo político à sua práxis, reconhecendo-se como prática social inserida em uma ampla e complexa trama relacional, marcada por conflitos socioambientais e crise de valores. A Carta de Belgrado e as recomendações da Conferência Intergovernamental sobre Educação Ambiental, promovida em 1977 em Tbilisi, já anunciavam a educação ambiental como área interdisciplinar e integradora das dimensões biológicas e culturais: 
A educação ambiental é o resultado de uma orientação e articulação de diversas disciplinas e experiências educativas que facilitam a percepção integrada do meio ambiente, tornando possível uma ação mais racional e capaz de responder às necessidades sociais (Recomendação no 1 da Conferência de Tbilisi).

Em 2003, quando a EA constitui-se como Grupo de Estudos na ANPEd, após haver ocupado espaço com apresentação de pesquisas e ensaios sobre o tema em outros Grupos de Trabalho, um longo caminho já havia sido trilhado a fim de construir uma identidade político-pedagógica para as atividades de pesquisa em EA no Brasil. Entretanto, a construção dessa identidade tem sido marcada pela pluralidade e ausência de um fundamento único, garantindo, assim, a multiplicidade de sentidos em disputa (CARVALHO, 2006, p. 33).

Para Sato e Santos (2003, p. 254), no final do século XX a EA deu um salto qualitativo, passando do "conservacionismo extremo a uma compreensão mais ampla de ambiente e natureza". O surgimento do termo socioambiental denota essa mudança de perspectiva no Brasil e na América Latina.

O diálogo entre esse campo socioambiental e o campo educacional, tema constitutivo da EA desde sua institucionalização na Conferência de Tbilisi, situa-se em uma esfera interdisciplinar, criando uma área de confluência marcada pela pluralidade temática, pela abordagem socioambiental mais ampla e por uma abertura epistemológica, que legitima as trocas e a complementaridade de saberes. Assim, a EA procura pensar-se como um campo de inovação e articulação capaz de fertilizar outros campos de saberes. Nesse sentido, surgem algumas questões, por exemplo: como essa área de confluência se constitui e que tendências são evidenciadas nessa esfera dialógica entre educação e meio ambiente?

É possível identificar autores, conceitos teóricos e metodologias dominantes ou a pluralidade é inerente a essa área? Que linhas transversais integram a diversidade do campo? Para responder a essa demanda de mapeamento das tendências da pesquisa em educação ambiental, o trabalho de investigação foi realizado da seguinte forma:

Considerando-se três eixos específicos: tendências temáticas, teóricas e metodológicas, foram realizadas análises preliminares desses trabalhos. A partir dessas análises, foram elaborados resumos descritivos de cada trabalho. Em seguida, foram criadas categorias de análises para interpretação das tendências nos três eixos de referências descritos acima, buscando-se preservar a singularidade da análise de cada eixo. O sentido de mapeamento apontou para a 
necessidade de localização temporal e espacial dessa produção e para a identificação de linhas transversais de articulação.

Para análise e interpretação dessa cartografia foram utilizadas quatro categorias, que orientaram a descrição e a reflexão sobre cada um dos eixos: 1) Evolução da temática EA na estrutura da ANPED; 2) Linha de tempo associada à diversificação temática, teórica e metodológica; 3) Localização espacial da produção acadêmica apresentada; e 4) A articulação entre a área ambiental, a de educação e a de educação ambiental (PATO; SÁ; CATALÃO, 2009, p. 215).

Com base nas quatro categorias de análise acima referidas, são apresentadas as tendências temáticas identificadas pela pesquisa.

\section{Tendências temáticas}

O mapeamento das tendências temáticas em EA nos trabalhos apresentados na ANPEd foi organizado em dois períodos distintos: o primeiro abrange os anos de 2003 e 2004, quando surge o Grupo de Estudos (GE) em EA. No segundo período, de 2005 a 2007, a EA adquire o status de Grupo de Trabalho (GT). Os temas recorrentes foram identificados e inseridos em uma linha temporal, observando-se a evolução da pesquisa em EA na ANPEd e a localização espacial que identifica a procedência dos trabalhos apresentados.

\section{$\underline{2003}$}

Esse ano, que marcou o início do Grupo de Estudos em EA nos encontros anuais da ANPEd, contou com treze trabalhos apresentados, entre artigos e pôsteres. Desses, doze trabalhos foram de universidades do Sudeste e do Sul do país; a contribuição acadêmica restante veio da região Norte.

Os temas foram reunidos em algumas categorias: reflexão teórica sobre fundamentos do campo e conceito de natureza e cultura; mapeamento e características de correntes de EA; sustentabilidade e desenvolvimento sustentável; transdisciplinaridade e paradigma; complexidade; ética e formação de valores; representação social sobre meio ambiente e percepção ambiental; relatos de pesquisas em EA desenvolvidas em espaços formais e não formais; formação de educadores e abordagens pedagógicas em EA. As concepções ambientais dos povos indígenas foram tema de um único trabalho apresentado pela região Norte, oriundo da Universidade Federal do Amazonas. Foi possível constatar uma distribuição bem equilibrada entre os estudos teóricos (06), as pesquisas em 
espaços de educação formal (08) e as realizadas em espaços não formais (05), ainda que predominem pesquisas sobre educação ambiental em espaços de educação formal.

Entre os estudos teóricos, nenhum tema teve ocorrência preponderante. Transdisciplinaridade, complexidade, mudança de paradigma, ética, concepções de natureza e cultura, sustentabilidade e representações sociais constituem o universo da expressiva pluralidade temática do campo nesse período.

Observa-se que o estudo das representações sociais apareceu em três trabalhos, enquanto a produção de materiais didáticos de EA foi um tema isolado. Com relação à educação formal, os temas interdisciplinaridade, construção da identidade, cidadania e formação de educadores marcaram presença. As questões pedagógicas em ambientes formais e não formais de aprendizagem ocuparam significativamente o foco das pesquisas e dos debates ambientais, tornando-se um campo fecundo de interlocução da educação com os problemas socioambientais.

Essa diversidade confirma a EA como um cenário epistemológico marcado pela pluralidade temática e pela convergência de múltiplos campos de saber articulados à mudança da relação homem-natureza. A questão ética apareceu de forma transversal, como princípio que sustenta a reflexão sobre a ação humana no mundo, a partir dos próprios sentidos dados pelas comunidades.

O cenário desse primeiro ano do GE em EA na ANPEd sugere que a pluralidade temática e a complementaridade de conhecimentos constituem o perfil do campo ecológico-ambiental quando este interage com a educação.

\section{$\underline{2004}$}

No ano seguinte, foram analisados quatorze trabalhos e mais uma vez predominaram as regiões Sul e Sudeste, com doze trabalhos, enquanto o Norte e o Nordeste apresentaram dois artigos.

As pesquisas voltadas para as relações entre as questões ambientais e a educação formal corresponderam a $50 \%$ do total dos trabalhos apresentados e versaram sobre o cotidiano escolar e o currículo. A pesquisa sobre EA em espaços educativos não formais responderam por apenas 14\% de artigos e pôsteres selecionados. Os ensaios teóricos referiam-se aos fundamentos e conceitos de EA, o papel da subjetividade e das representações sociais sobre meio ambiente, o papel da cultura e dos padrões relacionais entre sociedade e natureza, complexidade e sustentabilidade ambiental. 
Pela primeira vez, tomou-se o campo do trabalho para problematizar as concepções e as práticas de EA e os sentidos contraditórios dos conceitos de desenvolvimento sustentável. A contribuição da antropologia da ciência foi acionada para a complexa distinção entre biológico e social. Outros temas transdisciplinares, como globalização, cidadania e desenvolvimento sustentável, também foram abordados pelos ensaios teóricos nesse período, ampliando o diálogo entre os estudos de meio ambiente, sociedade e cultura. As discussões sobre interdisciplinaridade, transdisciplinaridade e práxis educativa apresentaramse como foco temático em grande número de artigos, na perspectiva de rede de conhecimentos e de comunidade ecológica.

A complexidade inerente aos processos educativos e aos processos socioambientais apareceu como tema em diversos trabalhos, mostrando um espaço de interlocução reflexiva na pesquisa e na discussão pedagógica em EA. A reflexão sobre formação de professores e representações sociais de estudantes, professores e educadores ambientais pontuou o universo temático da pesquisa nesse ano.

É notável que somente um trabalho apresentado refere-se à prática de educação ambiental em unidades de conservação, tendo como base as recomendações da Conferência Intergovernamental de Educação Ambiental de Tbilisi (1977), o que sugere um distanciamento da abordagem naturalista que predominou em EA nas décadas anteriores à Conferência Rio-92.

A compreensão do campo ambiental como construção social foi diretamente enfocada em três trabalhos, aparecendo, pela primeira vez, a denominação socioambiental como foco de reflexão e no título de um artigo. A pesquisa-ação e as pesquisas participantes foram objeto de pesquisa e reconhecidas como metodologias mais apropriadas à construção de conhecimentos em EA. O desenvolvimento sustentável foi discutido criticamente e inserido no âmbito do processo de globalização e do mundo do trabalho.

Percebe-se que o entendimento sobre os problemas ambientais passa por uma concepção de meio ambiente como um campo de conhecimento e de significados construídos socialmente, a partir de uma pluralidade de relações entre cultura, natureza e meio ambiente. O conhecimento em rede e a teia da vida se retroalimentam e produzem uma reflexão duplamente enraizada nas bases biológica e antropossocial.

\section{$\underline{2005}$}

O ano de 2005 marcou a passagem de Grupo de Estudos para Grupo de Trabalho de Educação Ambiental (GT 22) na ANPEd. Foram analisados dez 
trabalhos, todos procedentes do Sudeste e do Sul do país. Os artigos apresentados mostram um padrão comum e pode-se perceber uma preponderância das discussões pedagógicas no campo da EA.

Os debates sobre abordagem epistemológica e correntes de EA aprofundaram a temática e constaram em três trabalhos. A fenomenologia, a hermenêutica e a teoria das representações sociais apareceram pelo terceiro ano consecutivo como temática de estudos ou enfoque metodológico. A constituição identitária do campo da educação ambiental foi problematizada em dois estudos sobre as identidades do educador ambiental na formação inicial e continuada de professores.

A contribuição da arte em educação ambiental apareceu como tema emergente, com foco no texto literário e na contribuição da estética para a sensibilização ambiental. $\mathrm{O}$ debate sobre valores éticos e estéticos em EA foi tema de um trabalho, que discutiu a formação continuada de professores. Pela segunda vez, a cultura indígena apresentou-se como tema de discussão, agora abordando saúde e saneamento em comunidades indígenas.

\section{$\underline{2006}$}

Em 2006, nos dezesseis trabalhos analisados, confirmou-se a prevalência de instituições acadêmicas do Sudeste e Sul. Somente dois trabalhos foram provenientes da região Nordeste. Pode-se observar uma tendência crescente da pesquisa de campo e uma menor incidência de ensaios teóricos. Nestes, predominam a reflexão sobre concepções de natureza, de cultura e de educação, em um movimento notável de construção de identidade teórica desse novo campo de pesquisa e reflexão.

As pesquisas voltadas para o contexto escolar constituíram 50\% dos trabalhos apresentados, com destaque para um novo veio temático acerca da EA no ensino médio, na perspectiva da construção da cidadania, e para um artigo que tratou da contribuição da filosofia para a formação discente em educação ambiental. Um outro trabalho analisa coleções de livros didáticos com o objetivo de identificar as referências que sustentam as concepções de natureza, homem e sociedade nos livros didáticos do ensino fundamental.

Os demais trabalhos apresentados discutiram aspectos teóricos sobre fundamentos da EA (paradigma, complexidade, sustentabilidade e transdisciplinaridade), desenvolvimento e preservação ambiental e atuação de movimentos sociais e ONGs ambientalistas nos espaços não formais de EA. Pela segunda vez - a primeira foi em 2003 -, discutiu-se a EA na mídia televisiva, 
com foco nas produções da TV Cultura. Essa temática apareceu de forma isolada, não constituindo uma tendência expressiva.

\section{$\underline{2007}$}

Em 2007, foram analisados treze trabalhos, entre artigos e pôsteres, que confirmaram mais uma vez a tendência consolidada de localização da pesquisa acadêmica nas regiões Sul e Sudeste. O Centro-Oeste teve sua primeira aparição, com uma produção da Universidade de Brasília, e a região Nordeste apareceu com uma única contribuição da Universidade Federal do Ceará.

A formação de professores apresentou-se como temática predominante: formação de professores na educação de jovens e adultos, capacitação de professores das séries iniciais, formação de professores e transição de paradigmas, tendências da formação docente e das práticas de EA e a formação em EA no ensino superior constituíram os diversos enfoques de abordagem do tema.

Educação ambiental libertária e os fundamentos teóricos para uma pedagogia crítica da EA marcaram a produção de 2007. Essa linha temática veio a reafirmar a recorrência dos temas pedagógicos e o reconhecimento da EA como espaço de mediação entre a escola e os problemas ambientais contemporâneos. Outra linha temática expressiva, que aparecia com menos ênfase em outros trabalhos, apareceu como tema central de discussão. Trata-se da relação entre EA e educação popular em processos de alfabetização.

Construção de conhecimento, transição de paradigmas, cidadania e práxis pedagógica constituíram o foco de outros estudos analisados, que se situam na zona de articulação entre educação ambiental, educação e meio ambiente. As origens do distanciamento entre sociedade e natureza foram estudadas a partir da percepção ambiental de frequentadores de um parque municipal e de um estudo teórico que discute o sentido da alteridade na relação homem-natureza no contexto do currículo do ensino médio. A percepção de natureza é abordada sob a lente da cultura, confirmando a redução gradativa de temas que associam educação ambiental com o estudo das ciências da natureza.

As temáticas apresentadas na ANPEd no período de 2003 a 2007 mostram-se em consonância com aquelas apresentadas no Colóquio Internacional em Pesquisa sobre Educação Ambiental, realizado em Montreal em 1997, e referenciadas por Lucie Sauvé. As temáticas desse evento (SATO; SANTOS, 2003, p. 257) foram predominantemente marcadas por temas pedagógicos, formação de educadores e currículo (45\%), seguidas por discussão sobre fundamentos de EA, sociologia, filosofia, valores, atitudes (19\%). Todavia, 
as representações sociais estiveram presentes em $11 \%$ dos trabalhos, uma incidência maior do que a observada na ANPEd.

Nota-se no caso brasileiro uma tendência insurgente voltada para o estudo da educação ambiental não formal, especialmente em comunidades tradicionais e movimentos sociais. Além disso, há recorrência da pesquisa-ação como temática específica de alguns trabalhos, o que denota uma possível identidade para a educação ambiental brasileira como prática social voltada para a transformação social e formação humana.

\section{Considerações finais}

O cenário temático dos trabalhos analisados, assim como as referências teóricas e metodológicas mais recorrentes no relatório final da pesquisa (PATO; SÁ; CATALÃO, 2009), apontam algumas características do campo de Educação Ambiental bem distantes de abordagens fragmentadas, simplificadoras e naturalistas.

O diálogo entre a complexidade inerente ao próprio processo educativo e a complexidade do campo socioambiental delineia uma identidade crítica para a EA brasileira. Identidade inseparável da diversidade de olhares que buscam se distanciar de uma visão ingênua e redutora, pautada pelo reconhecimento de que os saberes que constituem o campo da educação ambiental são parte de uma intrincada rede de relações entretecida pelo contexto político, condições sociais, padrões culturais, processos produtivos e esquemas de poder.

Os sentidos da EA não se restringem a projetos interdisciplinares ou ao desenvolvimento de temas transversais ambientais, como propõem os Parâmetros Curriculares Nacionais (MEC, 1997). A educação ambiental está voltada à construção de sociedades sustentáveis e a educação é uma prática social que interfere e colabora nessa construção. Segundo Carvalho (2004), o educador ambiental, tomado desde uma perspectiva hermenêutica, poderia ser pensado como um intérprete das interpretações socialmente construídas.

Em termos da regionalização da produção acadêmica no país, os trabalhos apresentados no período analisado representam particularmente o eixo Sul-Sudeste. Isso pode indicar tanto a hegemonia dessas regiões como a necessidade de incentivar a participação das demais regiões brasileiras nesse espaço de divulgação e discussão acadêmica.

Essa predominância do eixo sul-sudeste pode refletir a consolidação de programas de pós-graduação, mas também a dificuldade de acesso de pesquisadores de regiões mais distantes da sede desse evento, além de custo 
elevado para submeter trabalhos e participar do mesmo (PATO; SÁ; CATALÃO, 2009, p. 230).

A presença dos temas e projetos pedagógicos nas escolas, a formação de professores e o reconhecimento da EA como espaço de mediação entre a escola e os problemas ambientais contemporâneos ocupam mais da metade dos temas enfocados nos trabalhos.

Destaca-se ainda a ênfase na discussão sobre a própria identidade política da EA e a recorrência da concepção de práxis educacional sustentada na visão de Paulo Freire, o que também se confirma no interesse pela pesquisa-ação e pesquisa participante, ora como tema de estudo, ora como metodologia de pesquisa.

Percebe-se, também, que esses estudos participativos enfatizam a intervenção na realidade, de forma a modificar a relação que os sujeitos têm consigo mesmos e com seu entorno. Isso pode sinalizar a vocação das pesquisas em educação ambiental para a transformação da realidade, em direção a relações mais sustentáveis para a pessoa, os grupos, a sociedade e o planeta, num processo de ação-reflexão-ação permanente (PATO; SÁ; CATALÃO, 2009, p. 232).

A abordagem socioambiental, que reconhece os aspectos políticos e culturais como constitutivos de uma nova postura epistemológica, crítica e implicada, predomina no conjunto dos trabalhos analisados, assim como o distanciamento de uma visão conservacionista e naturalista. Foi possível, também, identificar alguns temas transversais, como representações sociais, subjetividade, sustentabilidade, fenomenologia e hermenêutica, que confirmam a pluralidade de abordagens utilizadas para problematizar a conceituação da relação entre cultura e natureza.

O V EPEA, que teve como tema a Configuração do Campo de Pesquisa em Educação Ambiental, oportunamente propôs uma mesa-redonda reunindo os resultados da pesquisa sobre os trabalhos apresentados no GT 22 na ANPEd (PATO; SÁ; CATALÃO, 2008) com a pesquisa realizada por Clarice Sumi Kawasaki (USP) sobre os trabalhos acadêmicos discutidos nos EPEAs anteriores. Sob a mediação de Isabel Carvalho, o debate colocou em perspectiva esse cenário com a produção acadêmica apresentada em outros espaços. Seria oportuno que investigações dessa natureza fossem realizadas em outros fóruns nacionais e regionais de EA, bem como no GT de Meio Ambiente, Sociedade e Educação, da Associação Nacional de Pós-Graduação e Pesquisa em Ambiente e 
Sociedade - ANPPAS, a fim de identificar e aprofundar as discussões sobre a configuração do campo da pesquisa em Educação Ambiental e suas principais tendências em outros eventos.

No contexto da ANPEd, a pesquisa em educação ambiental revela-se mais uma vez como um campo de confluências marcado por uma epistemologia transdisciplinar e uma abordagem complexa de educação e meio ambiente. As práticas educativas na área de educação formal repertoriadas nos artigos analisados mostram a tendência para uma pedagogia crítica e emancipatória e confirmam que os grandes desafios para os educadores ambientais são, de um lado, resgatar e desenvolver valores e comportamentos (confiança, respeito mútuo, responsabilidade, compromisso, solidariedade e iniciativa) e, de outro, estimular uma visão global e crítica das questões ambientais.

O presente trabalho buscou delinear o cenário e as características da produção acadêmica na área de educação ambiental mostrando a emergência de aspectos temáticos. A partir do exposto, é possível inferir as omissões e os temas silenciados pelos pesquisadores da área, o que pode sugerir futuros campos para a investigação acadêmica.

\section{Referências}

CARVALHO, Isabel Cristina de Moura. Educação Ambiental: a formação do sujeito ecológico. São Paulo: Cortez, 2004.

Invenção e auto-invenção na construção psicossocial da identidade: a experiência constitutiva do educador ambiental. In: GUIMARÃES, Mauro (Org.). Caminhos da Educação Ambiental. Campinas: Papirus, 2006.

SATO, Michèle; SANTOS, José Eduardo. Tendências nas pesquisas em Educação Ambiental. In: NOAL, Fernando Oliveira; BARCELOS, Valdo Hermes de Lima (Org.). Educação Ambiental e Cidadania: cenários brasileiros. Santa Cruz do Sul: EDUNISC, 2003.

PATO, Claudia; SÁ, Lais Mourão; CATALÃO, Vera Lessa. Mapeamento de tendências na produção acadêmica sobre Educação Ambiental. Educação em Revista, Belo Horizonte, v. 25, n. 3, p. 213-224, dez. 2009.

Artigo: recebido em 23/11/2009 - aprovado em 21/12/2009 